\title{
LETTER
}

\section{Microstructural observations of fracture-filling goethite vein along the Kerajang Fault Zone in the Rengali Province of eastern India}

\author{
Takafumi YAмамото ${ }^{*, * *}$, Jun-ichi ANDo*, Naotaka TomioKA**, \\ Kaushik DAs ${ }^{*}$, Gautam GHosH ${ }^{* * *}$ and Sankar BosE ${ }^{* * *}$ \\ "Department of Earth and Planetary Systems Science, Hiroshima University, \\ 1-3-1 Kagamiyama, Higashi-Hiroshima, Hiroshima 739-8526, Japan \\ ${ }^{* *}$ Kochi Institute for Core Sample Research, Japan Agency for Marine-Earth Science and Technology, \\ 200 Monobe Otsu, Nankoku, Kochi 783-8502, Japan \\ ${ }^{* * *}$ Centre for Advanced Study, Department of Geology, Presidency University, 86/1 College Street, Kolkata 700073, India
}

\begin{abstract}
Microstructural observations and chemical composition analyses of a fracture-filling goethite vein in quartzite bands adjacent to a terrain-boundary fault zone were carried out, primarily using electron microscopy, to determine its formation process. Two domains A and B were identified, based on microstructural and chemical characteristics. The domain A formed a layered structure characterized by goethite grains with higher Al contents, smaller grain size (several hundred nanometers to micrometers in size), with development of the strong shape- and lattice-preferred orientations (SPO and LPO) of [020] and [110] along the wall rock contact, whereas the inner region had lower Al contents with larger grain size (several micrometers in size). The domain B exhibited concentric zoning characterized by variation in chemical composition, grain-size grading approximately ten to several tens of nanometers in size, a change in the porosity, and the alignment of goethite [110] perpendicular to the zoning plane. The grain size distribution and development of SPO and LPO in domain A can be explained by the inhibition of crystal growth (due to the incorporation of $\mathrm{Al}^{3+}$ instead of $\mathrm{Fe}^{3+}$ ) and geometrical selection, respectively. Two possible formation processes for domain B can be proposed based on the analogy of chalcedony; precipitation of goethite colloidal particles with electrophoretic force or heterogeneous nucleation from the Fe-rich supersaturated fluid and subsequent crystal growth. The study results suggest that the goethite vein was formed by multiple stages of Fe-rich fluid infiltration, which may have been derived from the Banded Iron Formation in the Singhbhum cratonic crust related to the activation of the Kerajang Fault Zone.
\end{abstract}

Keywords: Fracture-filling vein, Goethite, Fe-rich crustal fluid, Concentric zoning, Microstructure

\section{INTRODUCTION}

'Geofluid' has recently attracted the attention of geoscientists because it drastically changes the physical and chemical properties of rocks and affects various geological phenomena, including earthquake activity, magma generation, and ore deposit formation (e.g., Yardley and Bodnar, 2014; Kawamoto et al., 2015). The microstructures and chemical compositions of vein-filling minerals, such as calcite and quartz, are particularly well known as indicators of the fluid characteristics, deformation kinematics, and paleo-stress field (e.g., Nishikawa and Takeshita, 2000; Bons et al., 2012; Okamoto, 2014). Here, we

doi:10.2465/jmps. 161113

T. Yamamoto, tyamamoto@hiroshima-u.ac.jp Corresponding author report on a fracture-filling vein solely composed of goethite, present in quartzite bands along the Kerajang Fault Zone (KFZ) in the Rengali Province (RP) of eastern India. Microstructural observations and chemical analyses were carried out, primarily using electron microscopy, to determine the formation process of the goethite vein.

Glikson et al. (2008) reported on a fracture-filling goethite vein in the Hickman Crater in Western Australia, which is interpreted to have been formed by an impacttriggered cratering and subsequent hydrothermal process. The researchers considered the goethite to have originated from Fe leaching in groundwater from the neighboring formation. However, they did not describe the details of microstructures of the vein. The present study focuses on the formation process of a fracture-filing goethite vein. 

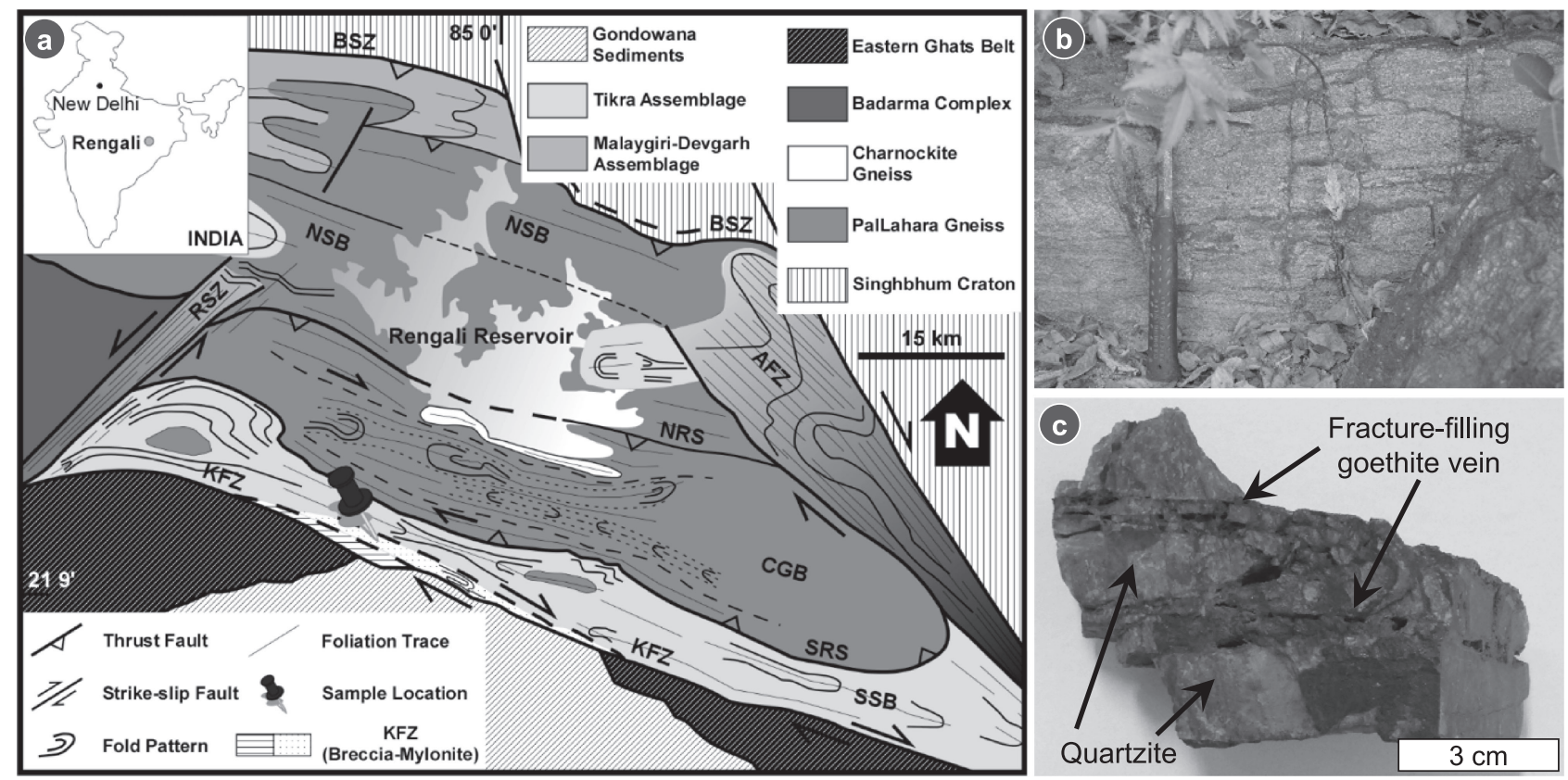

Figure 1. (a) Geological map of the study area around Rengali, showing the major lithological units, shear/fault zones, fold patterns, foliation traces, and sampling location (modified after Ghosh et al., 2016). KFZ, Kerajang Fault Zone; SSB, Southern Supracrustal Belt; CGB, Central Gneissic Belt; NSB, Northern Supracrustal Belt; BSZ, Barkot Shear Zone; RSZ, Riamol Shear Zone; AFZ, Akul Fault Zone; SRS, South Riamol Splay; NRS, North Riamol Splay. (b) Outcrop photograph of dark fracture-filling goethite vein in the weakly metamorphosed quartzite. (c) Rock chip of the quartzite, including the fracture-filling goethite vein.

\section{GEOLOGICAL BACKGROUND}

The RP is a unique terrane located at the eastern Indian cratonic margin, sandwiched between the Archean Singhbhum craton (SC) and the Proterozoic Eastern Ghats Belt (EGB) (Mahalik, 1994; Crowe et al., 2003) (Fig. 1a). The occurrence of deep-crustal rocks alongside middleto shallow-crustal rocks on the present-day erosional surface suggests a very complex history of structural and metamorphic evolution. The deep-crustal rocks include granulite, whereas the middle- to shallow-crustal rocks include medium- to low-grade metasedimentary to metaigneous rocks. The deep-crustal granulites preserve a Neoarchean history of tectonothermal evolution through orogenesis (e.g., Bose et al., 2016). The pressure-temperature $(\mathrm{P}-\mathrm{T})$ histories of mafic and pelitic granulites in the central gneissic belt of the RP were apparently different, which are high $\mathrm{P}-\mathrm{T}$ conditions $\left(10-12 \mathrm{kbar}, 860^{\circ} \mathrm{C}\right)$ and mid-crustal heating up to $730{ }^{\circ} \mathrm{C}$ at $6 \mathrm{kbar}$, respectively (Bose et al., 2015). Such a complex metamorphic evolution suggests the juxtaposition of crustal sections of different depths. This E-W-trending belt is bounded by major fault systems and separated from the northern SC by the E-W-trending Barkot shear zone and the southern EGB by another E-W-trending KFZ (Mahalik, 1994). The overall structural evolution is interpreted as the product of a crustal-scale flower structure in transpressional tectonics (Ghosh et al., 2016). Based on the structural geometry, the kinematic analysis, and in situ monazite $\mathrm{U}-\mathrm{Th}$-total $\mathrm{Pb}$ ages, the different crustal sections of the RP have been interpreted to have juxtaposed during the ca. 500 Ma tectonic event (Ghosh et al., 2016).

The present study was carried out in the central part of the RP, where the amphibolite- to granulite-grade central gneissic belt is flanked by two greenschist facies supracrustal belts, termed the Northern and Southern Supracrustal Belts (NSB and SSB) by Ghosh et al. (2016). The boundary between the SSB and the southerly placed EGB is marked by the KFZ. The immediate southern part of the KFZ, however, is now concealed by the undeformed Phanerozoic sedimentary basin fill (Gondwana Basin). Samples for the present study were collected from the $\mathrm{SSB}$, where the rock types include quartzite, muscovite schist, and calc-schist. Fracture-filling goethite veins with widths of a few centimeters occur in quartzite (Figs. $1 \mathrm{~b}$ and $1 \mathrm{c}$ ), which is developed mostly parallel to the preexisting foliation, forming networks in some places. In a locality southeast $(\sim 20 \mathrm{~km})$ of the studied area, close to the southernmost boundary of the KFZ, thick foliationparallel brecciated zones filled by black minerals with widths on the order of $10 \mathrm{~cm}$, which are likely to be thick goethite veins, are also present in the same quartzite unit. This indicates that fracture-filling goethite veins occur widely along the southern margin of the KFZ. 


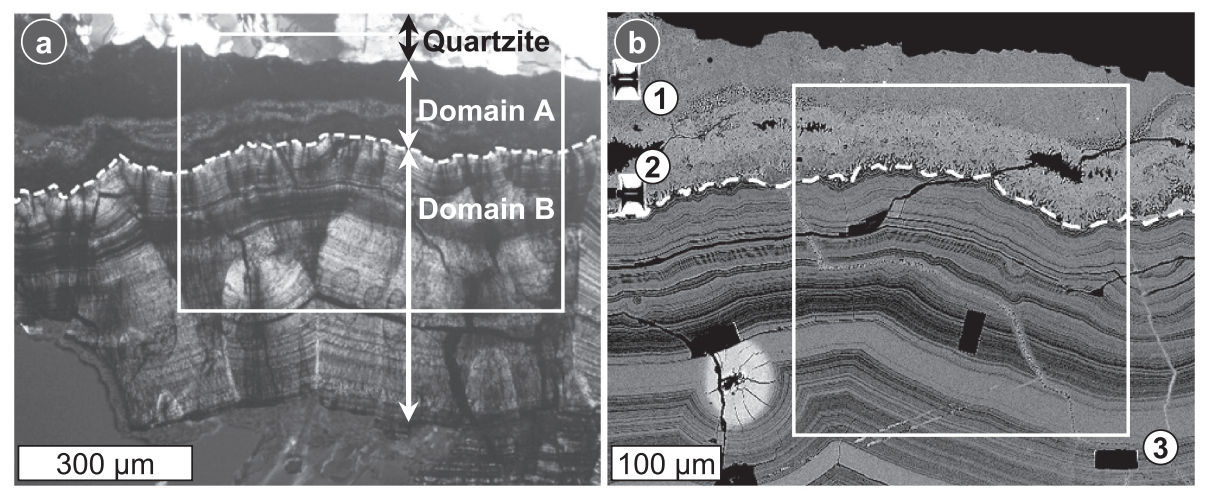

Figure 2. (a) Optical photomicrograph of one half of the fracture-filling goethite vein under cross-polarized light. The broken line represents the boundary between the domains $\mathrm{A}$ and $\mathrm{B}$. The inset rectangle shows the location of the magnified area in image (b), BSI. (b) Differences in microstructures between the domains $\mathrm{A}$ and $\mathrm{B}$. The numbers indicate the locations where the TEM thin foils were made using FIB. The inset rectangle indicates the area of EPMA elemental mapping, the results of which are shown in (c). (c) Elemental maps of Si, P, $\mathrm{Al}$, and Fe. The black rectangles on each map indicate the trace of FIB processing. The pores are filled by Si-rich materials.

\section{ANALYTICAL METHODS}

Polished thin sections were observed using an optical microscope. Backscattered electron imaging (BSI) and chemical composition mapping of the vein in one of the polished thin sections were carried out using an electron probe microanalyzer (EPMA; JEOL JXA8200) at the Natural Science Center for Basic Research and Development (N-BARD) of Hiroshima University. Raman spectroscopy was carried out on a Renishaw inVia Raman Reflex microscope equipped with a Leica DMLM microscope at Hiroshima University. The Raman spectra were excited with a 532-nm LD laser and identified by reference to Hanesch (2009). Thin foils for transmission electron microscopy (TEM) and scanning transmission electron microscopy (STEM) were prepared using a focused-ion-beam (FIB) machine (Hitachi SMI4050) at the Kochi Institute for Core Sample Research (KOCHI) of the Japan Agency for Marine-Earth Science and Technology. TEM and STEM observations were conducted using the JEOL JEM-2010 at N-BARD and the JEOL JEMARM200F at KOCHI, operated at an accelerating voltage of $200 \mathrm{kV}$. STEM was also used for high-angle annular dark-field (HAADF) imaging, in which the contrast is sensitive to the average $\mathrm{Z}$ number, and energy dispersive $\mathrm{X}$-ray spectroscopy (EDS) analysis.

\section{RESULTS}

The microstructures inside the vein are symmetrically arranged with respect to the center of the vein. One half of the vein, from the vein wall to the center, was divided into

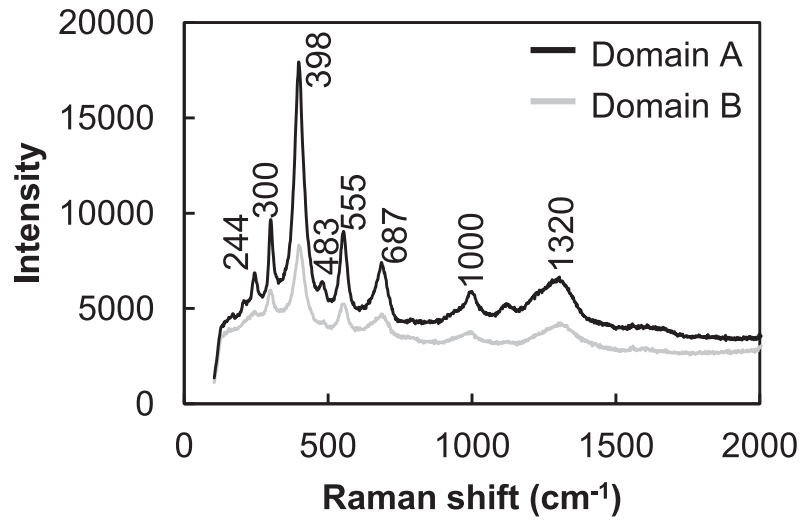

Figure 3. Representative Raman spectra obtained from the domains A and B. These spectra are comparable with those for goethite reported by Hanesch (2009).

domains $\mathrm{A}$ and $\mathrm{B}$, based primarily on differences in the transmitted colors and grain sizes (Fig. 2a). All of the Raman spectra obtained from the domains A and B were identified as goethite, based on the combination of the strongest band at $398 \mathrm{~cm}^{-1}$ and sharp bands around 244, $300,483,555,687,1000$, and $1320 \mathrm{~cm}^{-1}$ (Fig. 3). Therefore, the difference between the domains $\mathrm{A}$ and $\mathrm{B}$ are not due to mineralogical compositions, but due to the microstructural differences of goethite, primarily depending on their grain sizes. The grain sizes of the goethite in the domains $\mathrm{A}$ and $\mathrm{B}$ are several hundred nanometers to micrometers and ten to several tens of nanometers, respectively.

In addition to the variation of goethite grain size mentioned above, the domains A and B show different characteristics, in terms of their chemical compositions, 

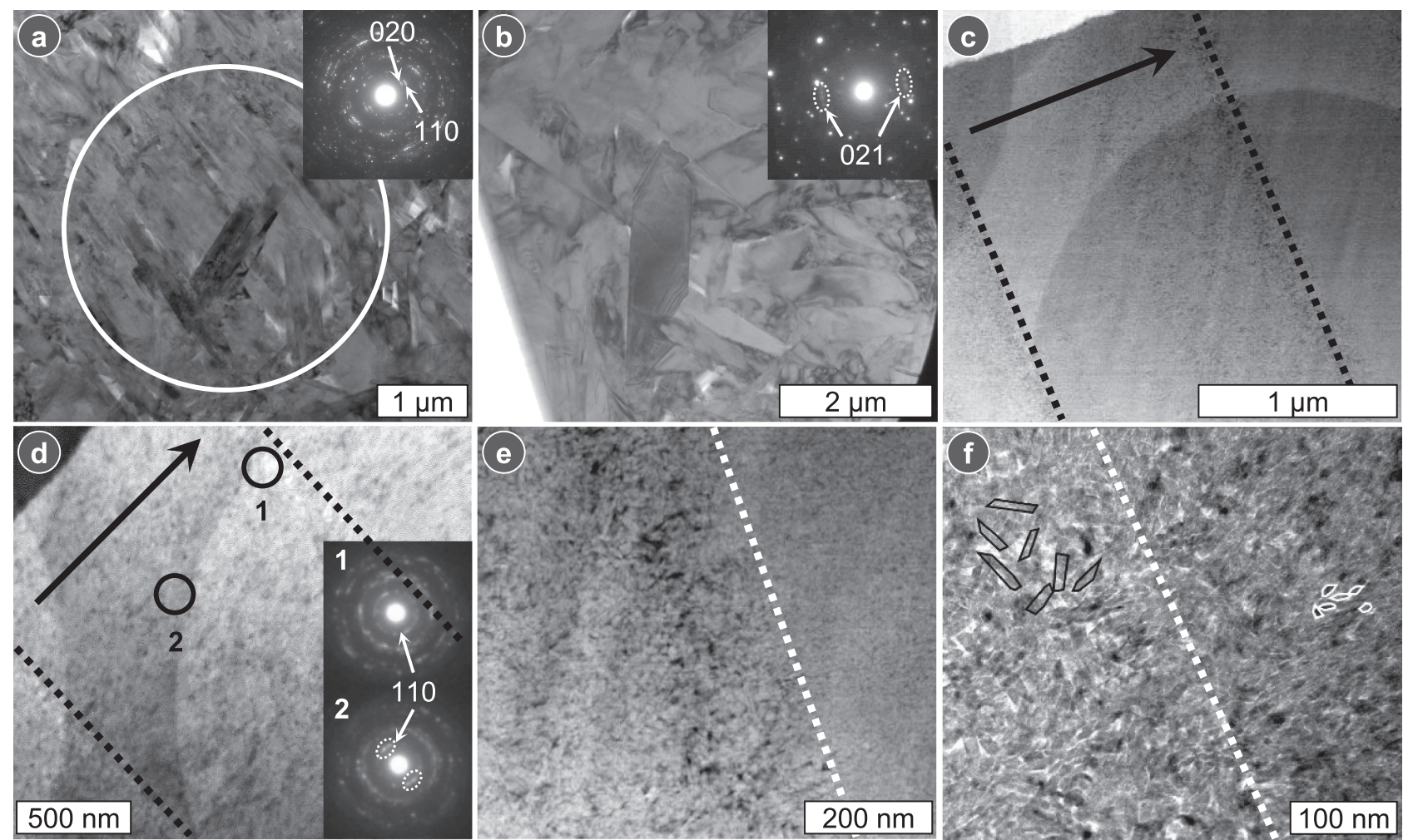

Figure 4. TEM (a), (b), (d), and (f) and STEM (c) and (e) images of goethite grains. These thin foils were made from the areas numbered 1 for (a), 2 for (b), and 3 for (c) to (f) in Figure 2b. The SAED patterns in (a) and (d), which were collected from the areas indicated by the circles in each image, can be identified as goethite (orthorhombic space group Pbnm, $a=4.5979(2) \AA, b=9.9510(5) \AA, c=3.0178(1) \AA$, Yang et al., 2006). The electron diffraction pattern in (b) was collected without a selected-area aperture and also identified as goethite. The broken lines in (c) to (f) show the boundaries of the concentric zoning. The solid arrows in (c) and (d) indicate the direction perpendicular to the zoning plane. The large circles in the background of (c) and (d) are holes in the carbon support film. The dark-contrast dots in the HAADF images represent the presence of lighter elements or pores. (a) Bright-field (BF) image of acicular-shaped goethite grains. The SAED pattern shows that goethite grains develop the strong LPO of [020] and [110]. (b) BF image of goethite grains with weak LPO of [021]. The grain size of the goethite is greater than those in (b). (c) HAADF image of the concentric zoning. The NNE-SSW trend lines are artifacts created by the Ga ion beam during the FIB preparation. (d) BF image of the same area shown in (c). The SAED pattern shows that goethite grains develop the weak LPO of [110]. (e) Magnified HAADF image at the boundary of the concentric zoning. The porous area with larger goethite grains (on the left-hand side in the figure) and the densely packed area with smaller goethite grains (on the right-hand side) are adjacent to each other. (f) Magnified BF image of the same area shown in (e). The solid lines represent the trace of the individual goethite grains.

the degrees of shape- and lattice-preferred orientations (SPO and LPO), and porosities. The domain A exhibits alternation of layers with a few hundred micrometers thick (Fig. 2b), and the $\mathrm{Al}$ contents of each layer are different (Fig. 2c). According to the TEM results, the layer in contact with the vein wall has a higher Al content (Fig. 2c) and its goethite grains are acicular in shape and several hundred nanometers to micrometers in size (Fig. 4a). These goethite grains exhibit the strong SPO and LPO of [020] and [110], as indicated by the selected-area electron diffraction (SAED) pattern (Fig. 4a). On the other hand, the goethite grains in the layer with a lower $\mathrm{Al}$ content are larger (several micrometers in size) (Fig. 4b). These goethite grains exhibit a weak LPO of [021], as indicated by the SAED pattern (Fig. 4b).

The domain B exhibits a lower Fe content than do- main $\mathrm{A}$ and concentric zoning resulting from variations in the grain size and chemical composition (Fig. 2). The grain size of goethite in the single layer gradually increases from approximately ten to several tens of nanometers in size from the boundary of the domain A to the center of the vein (Figs. 4c-4f). The porosity of the single layer increases with increasing grain size (Figs. $4 \mathrm{c}$ and $4 \mathrm{e}$ ). The SAED patterns show that the [110] of the goethite grains tend to be arranged perpendicular to the zoning plane, except for the coarse-grained goethite at the top of the single layer (Fig. 4d). The concentric zoning is unique in terms of the compositions of $\mathrm{Si}, \mathrm{P}$, and Al. The layers with higher Si contents almost correspond to those with higher $\mathrm{P}$ contents, whereas the Al content is inversely correlated with the Si and P contents (Fig. 2c). The chemical composition of the single layer is homogeneous, ac- 


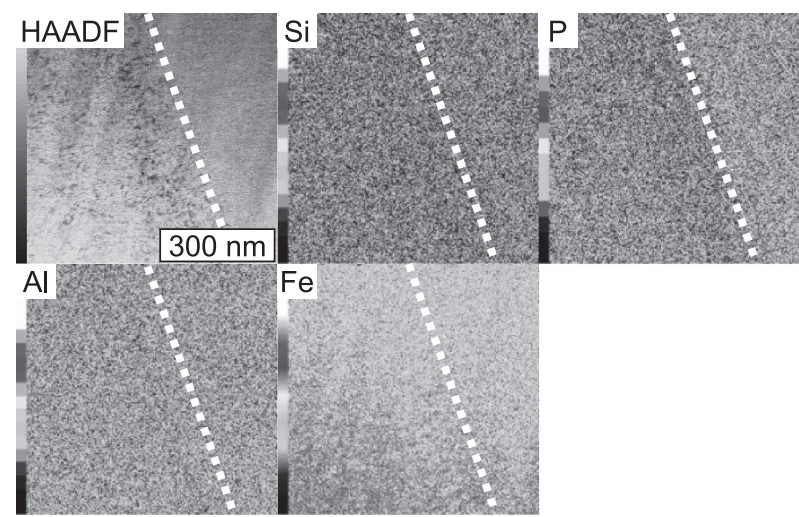

Figure 5. HAADF image and STEM-EDS maps of $\mathrm{Si}, \mathrm{P}, \mathrm{Al}$, and $\mathrm{Fe}$ of the area shown in Figure 4e. The broken lines show the boundaries of the concentric zoning. The variation in the content of $\mathrm{Fe}$, which is the major element of goethite, reflects the variation in thickness of the foil.

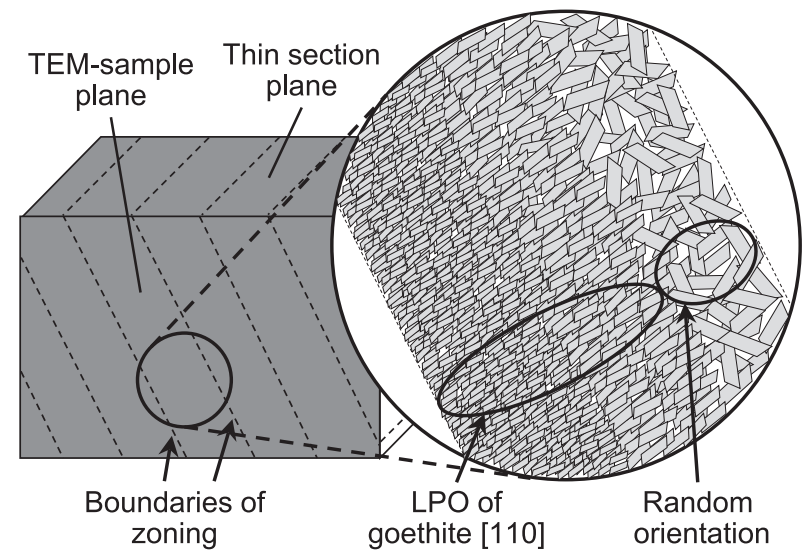

Figure 6. Schematic diagram of the microstructure of the concentric zoning in the domain $\mathrm{B}$.

cording to the STEM-EDS maps (Fig. 5). A schematic diagram of the microstructures of the concentric zoning is shown in Figure 6.

\section{DISCUSSION}

Microstructural observations suggest that the studied vein was formed from a fluid by fracture-filling process. The formation processes of both domains $\mathrm{A}$ and $\mathrm{B}$ can be explained as follows. The grain size distribution of the goethite in the domain A was influenced by the $\mathrm{Al}$ content of the original fluid. The Al content of the smaller goethite grains, initially crystallized along the wall, was much higher than that of the larger goethite grains crystallized later (Figs. 2c, 4a, and 4b). This might have resulted from inhibition of crystal growth by the substitution of $\mathrm{Al}^{3+}$ for $\mathrm{Fe}^{3+}$ (Bazilevskaya et al., 2012). These goethite grains developed the LPO and SPO, which are considered to be formed by geometrical selection due to anisotropic growth kinetics and competitive growth during the nucleation and growth stages (e.g., Sunagawa, 2005).

The concentric zoning with grain-size grading in the domain B, which is similar to that of chalcedony (e.g., Taijing and Sunagawa, 1994; Heaney and Davis, 1995), can be explained by crystallization resulting from multiple stages of interaction of fluid with different chemical compositions. The microstructural similarity with chalcedony suggests two possible formation processes: precipitation from a colloidal fluid with electrophoretic force (Taijing and Sunagawa, 1994) or a supersaturation-nucleation-depletion cycle (Heaney and Davis, 1995; French et al., 2013). In the former case, our microstructural observation implies that smaller colloidal particles of goethite in the Fe-rich fluid are more easily attracted to the wall by electrophoretic force than larger particles are. In the latter case, intense nucleation of goethite grains in the Fe-rich supersaturated fluid, i.e., heterogeneous nucleation, initially occurs at numerous sites along the interfacial boundary between the fluid and the vein wall. This phenomenon probably prevents the growth of individual goethite grains and decreases the saturation level through the formation of numerous goethite nucleation sites, which subsequently promotes less nucleation and more grain growth to larger sizes. At present, we cannot pinpoint which of these two processes is responsible for the formation observed.

The source of fracture-filling Fe-rich fluid is intriguing because the goethite vein observed was developed in quartzite. One possible source of the Fe-rich fluid is the Banded Iron Formation (BIF), which is the same situation of the goethite vein found in the Hickman Crater (Glikson et al., 2008). The BIF-bearing Iron Ore Group is widely distributed in the southern part of the SC, presently bounded at the north of the RP (e.g., Saha, 1994). A recent study on gravity anomalies suggested that the cratonic crust, one of the main components of which is the BIF, exists below the surface distribution of the RP (Mandal et al., 2015). These facts suggest that the BIF may be the source of the Fe-rich fluid. However, geochemical data, such as trace elements and isotopic compositions, are needed to confirm the exact origin of the Fe-rich fluid.

The goethite vein is presently found only along the KFZ in the studied area. The preliminary results of the vein orientation measurements suggest that the veins are mostly parallel to the E-W strike direction of the associated quartzites and the boundary fault (KFZ) between the RP and the Gondwana basin. Bose et al. (2016) and Ghosh et al. (2016) have demonstrated that the KFZ was reactivated during the opening-up of the Phanerozoic 
Gondwana basin and at relatively shallower depth. Considering these findings, we conclude that the formation of the studied goethite vein may have been related to the latest tectonic activity of the KFZ in the RP. More detailed analyses of the vein orientations may provide a better understanding of the relation between the goethite vein formation and tectonic activity around the KFZ.

\section{ACKNOWLEDGMENTS}

The authors thank Y. Shibata of N-BARD at Hiroshima University for his support of the EPMA measurements. We are grateful to H. Hidaka of Nagoya University for his support of the Raman spectroscopy analysis. A. Dasgupta of the Government General Degree College and Y. Hayasaka of Hiroshima University are also appreciated for their assistance in the field work. We also thank two reviewers for their critical comments and suggestions that helped to improve this manuscript. This study was carried out as part of the DST-JSPS Bilateral Research Program (DST/INT/JSPS/P-190/2014).

\section{REFERENCES}

Bazilevskaya, E., Archibald, D.D. and Martínez, C.E. (2012) Rate constants and mechanisms for the crystallization of $\mathrm{Al}$ nanogoethite under environmentally relevant conditions. Geochimica et Cosmochimica Acta, 88, 167-182.

Bons, P.D., Elburg, M.A. and Gomez-Rivas, E. (2012) A review of the formation of tectonic veins and their microstructures. Journal of Structural Geology, 43, 33-62.

Bose, S., Guha, S., Ghosh, G., Das, K. and Mukhopadhyay, J. (2015) Tectonic juxtaposition of crust and continental growth during orogenesis: Example from the Rengali Province, eastern India. Geoscience Frontiers, 6, 537-555.

Bose, S., Das, K., Kimura, K., Hidaka, H., Dasgupta, A., Ghosh, G. and Mukhopadhyay, J. (2016) Neoarchean tectonothermal imprints in the Rengali Province, eastern India and their implication on the growth of Singhbhum Craton: Evidence from zircon U-Pb SHRIMP data. Journal of Metamorphic Geology, 34, 743-764.

Crowe, W.A., Nash, C.R., Harris, L.B., Leeming, P.M. and Rankin, L.R. (2003) The geology of the Rengali Province: Implications for the tectonic development of northern Orissa, India. Journal of Asian Earth Sciences, 21, 697-710.

French, M.W., Worden, R.H. and Lee, D.R. (2013) Electron backscatter diffraction investigation of length-fast chalcedony in agate: Implications for agate genesis and growth mechanisms.
Geofluids, 13, 32-44.

Ghosh, G., Bose, S., Das, K., Dasgupta, A., Yamamoto, T., Hayasaka, Y., Chakrabarti, K. and Mukhopadhyay, J. (2016) Transpression and juxtaposition of middle crust over upper crust forming a crustal scale flower structure: Insight from structural, fabric, and kinematic studies from the Rengali Province, eastern India. Journal of Structural Geology, 83, 156-179.

Glikson, A.Y., Hickman, A.H. and Vickers, J. (2008) Hickman Crater, Ophthalmia Range, Western Australia: Evidence supporting a meteorite impact origin. Australian Journal of Earth Sciences, 55, 1107-1117.

Hanesch, M. (2009) Raman spectroscopy of iron oxides and (oxy) hydroxides at low laser power and possible applications in environmental magnetic studies. Geophysical Journal International, 177, 941-948.

Heaney, P.J. and Davis, A.M. (1995) Observation and origin of self-organized textures in agates. Science, 269, 1562-1565.

Kawamoto, T., Nakajima, J., Reynard, B. and Toh, H. (2015) Special issue "Geofluid processes in subduction zones and mantle dynamics". Earth, Planets and Space, 67, 1-4.

Mahalik, N.K. (1994) Geology of the contact between the Eastern Ghats Belt and North Orissa Craton, India. Journal of the Geological Society of India, 44, 41-51.

Mandal, A., Gupta, S., Mohanty, W.K. and Misra, S. (2015) Subsurface structure of a craton-mobile belt interface: Evidence from geological and gravity studies across the Rengali Province-Eastern Ghats Belt boundary, eastern India. Tectonophysics, 662, 140-152.

Nishikawa, O. and Takeshita, T. (2000) Progressive lattice misorientation and microstructural development in quartz veins deformed under subgreenschist conditions. Journal of Structural Geology, 22, 259-276.

Okamoto, A. (2014) Vein texture: a window for fluid dynamics in the crust (in Japanese with English abstract). Japanese Magazine of Mineralogical and Petrological Sciences, 43, 25-29.

Saha, A.K. (1994) Crustal evolution of Singhbhum-North Orissa, India (Memoir No. 27). pp. 341, Geological Society of India, Bangalore.

Sunagawa, I. (2005) Crystals: growth, morphology and perfection. pp. 295, Cambridge University Press, New York.

Taijing, L. and Sunagawa, I. (1994) Texture formation of agate in geode. Mineralogical Journal, 17, 53-76.

Yang, H., Lu, R., Downs, R.T. and Costin, G. (2006) Goethite, $\alpha-$ $\mathrm{FeO}(\mathrm{OH})$, from single-crystal data. Acta Crystallographica Section E Structure Reports Online, 62, i250-i252.

Yardley, B.W.D. and Bodnar, R.J. (2014) Fluids in the continental crust. Geochemical Perspectives, 3, 1-127.

Manuscript received November 13, 2016

Manuscript accepted April 5, 2017

Manuscript handled by M. Satish-Kumar 